\title{
O gênero discursivo quadra popular: subsídios para leitura e escrita na escola
}

\section{The discourse genre popular verse: support for reading and writing at school}

\section{Wildman dos Santos Cestari*}

\begin{abstract}
RESUMO: Este artigo visa a caracterizar o gênero discursivo quadra popular a fim de que essa caracterização possa, futuramente, subsidiar a elaboração de sequências didáticas de leitura e produção escrita desse gênero. Atem-se à historicidade, às condições de produção, circulação, a elementos temáticos, enunciativos, composicionais e estilísticos. A pesquisa fundamentou-se no conceito bakhtiniano de gênero discursivo e em autores que dialogam sobre a versificação de formas poéticas orais, tradicionais e literárias em suas diversas manifestações sociais. Qualitativamente, investigou-se um corpus de 44 quadras populares coletadas de $A$ Trova (1973), A Trova Popular (1974), Tradições Populares (1976), A trova do Brasil (1972), Música, doce música (1976), As melodias do boi e outras peças (1989), 0 Bumba-meu-boi som e movimento (2011), Música de Feitiçaria no Brasil (1963), Manual de Versificação Românica (2003), Manual de danças gaúchas (1955) e de + 1001 quadrinhas populares da Vovó Anita (2008). Os resultados mostram que a quadra popular no Brasil é um gênero discursivo que se caracteriza por ser plasmado no molde português, cujo afeiçoamento se dá por um processo formular, apoiado no princípio da variação. Conservando por "muletas iniciais" e "finais" ou "chavões" muitas temáticas de origem, mas com adaptações já nacionalizadas. Conclui-se que essas características do gênero discursivo quadra popular no Brasil podem subsidiar um trabalho de leitura e produção escrita em sala de aula nos Ensinos Fundamental e Médio.
\end{abstract}

PALAVRAS-CHAVE: Gênero discursivo. Quadrinha popular. Sequência didática.

ABSTRACT: This article aims at characterizing the discourse genre popular block so that this characterization may in future support the development of didactic sequences of reading and written production of this context. Hang on to the historicity, the conditions of production, circulation, thematic elements, enunciation, compositional and stylistic. The research was based on Bakhtin's concept of speech genres and authors that dialogue about the versification of oral poetry, and traditional literary forms in their various social events. Qualitatively, we investigated a corpus of 44 popular blocks collected from the Trova (1973), People Trova (1974), Popular Traditions (1976), ballad of Brazil (1972), Music, sweet music (1976), melodies of the ox and other parts (1989), Bumba-meu-boi sound and movement (2011), Witchcraft Music in Brazil (1963), Versification Romanesque Manual (2003), Manual of gaucho dances (1955) and + 1001 popular rhymes Grandma Anita (2008). The results show

\footnotetext{
* Mestrando em Linguística Aplicada. Especialização em Literatura e graduação com licenciatura português-francês. Poeta inscrito na União Brasileira de Escritores - UBE, com três livros publicados. E-mail: wildmancestari2010@hotmail.com.
} 
that the popular court in Brazil is a discursive genre that is characterized by being enshrined in the Portuguese mold, whose afeccionment occurs by a process to formulate, supported the principle of variation. Saving for "initial crutches" and the "final" or "buzzwords", many thematic source, but with adaptations already nationalized. It was concluded that these features of speech genre popular block in Brazil can support a reading and written production work in the classroom in both Elementary and High School contexts.

KEYWORDS: Discursive genre. Popular rhyme. Instructional sequence.

\section{Introdução}

Os estudos desenvolvidos pela Linguística Aplicada têm apontado novas perspectivas no que concerne ao ensino da língua. Os Parâmetros Curriculares Nacionais - PCN (BRASIL, 1998), ao procurar romper com o método tradicional de ensino da Língua Portuguesa, vêm assinalando que as atividades de produção escrita e de fala devem primar pela interlocução efetiva como um ato marcadamente discursivo. Uma interação que envolve produtores, receptores e determinada situação sócio-histórica. Desse modo, o estudo dos gêneros discursivos na escola constitui uma iniciativa positiva de circulação, de apropriação de meios linguísticos e das diversas linguagens em que se dá a expressividade da comunicação verbal.

Por outro lado, tem-se verificado como a proposta simplificada dos livros didáticos vem trabalhando a poesia, enfocando-a quase que, exclusivamente, como base de interpretação textual. Esse tratamento dado à poesia tem dificultado abordar aspectos que poderiam ampliar as fronteiras de entendimento desse gênero discursivo em suas diversas manifestações.

Em se tratando mais especificamente da quadra, denominada trova, observa-se que os livros didáticos têm dado pouca ênfase ao estudo desse gênero poético. Geralmente, quando a enfatizam, fazem simplesmente associação ao folclore. Contudo, sem qualquer menção específica que penetre mais profundamente na questão, a ponto de atingir, por exemplo, o processo formular tradicional que a caracteriza. Fenômeno que se acha apoiado no princípio da variação, cujo modelo típico encontra-se plasmado nas formas 
cristalizadas das conhecidas quadras populares tradicionais de origem portuguesa que, amplamente difundidas, desde a colonização no Brasil, recebem, afetuosamente, a denominação de quadrinhas. Ou, então, consideram-na apenas como mera produção avulsa, independente e destituída de correlação com a corrente tradicional. Também não se questionam, ao menos, se poderia haver alguma distinção entre essas quadras populares tradicionais, desinteressadas de qualquer pretensão artística, da sua congênere erudita, de cunho literário e com status de obra de arte poética propriamente dita.

Vale ainda ressaltar, além do problema exposto acima, a falta de empolgação observada, para não dizer descaso, como os livros didáticos têm margeado a caracterização da quadra, quer na sua manifestação popular ou erudita. Em muitos casos prevalece uma definição mais vaga do que precisa, consequentemente, pouco auxiliando o professor que pretenda se debruçar em um estudo mais sistemático do gênero. Por isso se torna presente, cada vez mais, a necessidade de se trabalhar as especificidades dos gêneros do discurso na sala de aula. Observando, principalmente, em sua caracterização, seus elementos compositivos não apenas de forma, mas também de linguagem, de temáticas, de enunciação e de estilo, assim como seu objetivo comunicativo ao qual se vinculam as condições de produção, de recepção e de circulação social.

Nesse sentido, romper com a proposta simplificada de como os livros didáticos, muitas vezes, tratam o estudo dos gêneros, constitui um esforço essencial, sobretudo, no que tange à promoção de uma melhor qualidade de ensino e aprendizagem dos mesmos. Nessa perspectiva, a pesquisa na qual se apoia este artigo buscou obter respostas fundamentadas na concepção de gêneros discursivos de linha bakhtiniana. Mediante esse delineamento, surgiu a seguinte problematização: como a caracterização do gênero da quadra popular pode constituir-se em conhecimentos para subsidiar uma proposta de trabalho com leitura e produção escrita desse gênero nos ensinos Fundamental e Médio?

Partindo do problema delineado, essa proposição faz-se plausível quando se parte da premissa de que um gênero não é algo fixo e cristalizado, mas 
dinâmico. Os gêneros do discurso são "tipos relativamente estáveis" (BAKHTIN, 2011, p. 262). Entendê-los pressupõe reconhecer o seu processo de constante reelaboração, o contexto de enunciação, o tema, a composição e o estilo. Assim, a pesquisa tem como objetivo geral: caracterizar o gênero discursivo quadra popular como proposta pedagógica a fim de promover o ensino e a aprendizagem do mesmo como subsídio para o desenvolvimento, futuramente, de sequência didática de leitura e produção escrita na sala de aula dos Ensinos Fundamental e Médio.

A investigação de um gênero discursivo pressupõe considerar que ele se liga à história da sociedade e pode se realizar por meio de diversas manifestações e variadas características. Nesse sentido, o estudo do gênero discursivo quadra popular apresenta-se como um recurso pedagógico de grande alcance para o entendimento e a conscientização dos alunos e professores sobre a diversidade dos gêneros, das situações de enunciações e de suas funcionalidades, tão vivamente integrados à vida social.

De modo mais específico, ao pretender a caracterização do gênero discursivo quadra popular, buscou-se ater-se à sua historicidade, verificando ainda suas condições de produção e circulação, seus elementos temáticos e enunciativos, sua composição e seu estilo.

A pesquisa fundamentou-se no conceito bakhtiniano de gênero discursivo e em autores que dialogam sobre a versificação de formas poéticas orais, tradicionais e literárias em suas diversas manifestações sociais. Qualitativamente, investigou-se um corpus de 44 quadras populares, coletadas de A Trova (1973), A Trova Popular (1974), Tradições Populares (1976), A trova do Brasil (1972), Música, doce música (1976), As melodias do boi e outras peças (1989), O Bumba-meu-boi som e movimento (2011), Música de Feitiçaria no Brasil (1963), Manual de Versificação Românica (2003), Manual de danças gaúchas (1955) e de + 1001 quadrinhas populares da Vovó Anita (2008).

\section{Elementos para a caracterização de um gênero discursivo}


Os gêneros do discurso, segundo Bakhtin (2011, p. 266), são "determinados tipos de enunciados estilísticos, temáticos e composicionais relativamente estáveis". Correspondem a "situações típicas da comunicação verbal" (BAKHTIN, 2011, p. 293), referem-se aos "diversos campos da atividade humana" (BAKHTIN, 2011, p. 264).

$O$ conceito de linguagem que se institui de modo imperativo na ótica bakhtiniana é a da "ideia básica de que todo fato de significação é resultado de um trabalho social, realizado por sujeitos ativos no processo de interação/troca/comunicação verbal" (OLIVEIRA, 2002, p. 129). Desse modo, é na linguagem e pela instrumentalização da mesma, tendo o gênero como suporte, que o sujeito interage com o outro e apreende a realidade.

O gênero discursivo como suporte através do qual a comunicação humana se efetiva pela prática da linguagem, de acordo com Schneuwly e Dolz (2004), apresenta três dimensões essenciais que o define:

\begin{abstract}
1) os conteúdos e os conhecimentos que se tornam dizíveis por meio dele; 2) os elementos das estruturas comunicativas e semióticas partilhadas pelos textos reconhecidos como pertinentes ao gênero; 3) as configurações específicas de unidades de linguagem, traços, principalmente, da posição enunciativa do enunciador e dos conjuntos particulares de sequências textuais e de tipos discursivos que formam sua estrutura. (SCHNEUWLY; DOLZ, 2004, p. 64).
\end{abstract}

Com base nessas especificações é que se diz que os gêneros podem ser ensinados e aprendidos, já que instrumentalizam uma determinada forma de dizer e de se estabelecer com o outro um diálogo. Para Schneuwly e Dolz (2004, p. 64-5), "do ponto de vista do uso e da aprendizagem, o gênero pode, assim, ser considerado um megainstrumento que fornece um suporte para a atividade, nas situações de comunicação, e uma referência para os aprendizes".

Entretanto, é no espaço da escola que o gênero passa a ser ressignificado, "há um deslocamento que se opera em que o gênero não é mais instrumento de comunicação somente, mas é, ao mesmo tempo, objeto de ensino-aprendizagem" (SCHNEUWLY; DOLZ, 2004, p. 65). O gênero, nesta 
instância, "transforma-se em forma de expressão do pensamento, da experiência ou da percepção" (SCHNEUWLY; DOLZ, 2004, p. 65).

A organização, dessa maneira, das atividades escolares em função do princípio de uma sequência didática, consiste em pensar o ensino e a aprendizagem dentro de uma sistematização do conhecimento. Destarte, de acordo com Dolz e Schneuwly (apud MARCUSCHI, 2008, p. 213), uma sequência didática é tida como "um conjunto de atividades escolares organizadas, de maneira sistemática, em torno de um gênero textual oral ou escrito".

Nesse aspecto, há que se considerar a relação do evento em si como prática de algo a se ensinar e a se aprender, com a maneira de como se arquitetar a aplicação desta prática como tal. Um processo que envolve não apenas o conteúdo, mas ainda a sua organização em forma de estrutura, de modulações e de modos de composição de seus elementos característicos e estruturais.

Em concordância com esses pressupostos teóricos, Lopes-Rossi (2012) entende que, nos estudos com gêneros discursivos, contemplados por projetos de leitura e produção escrita, deve-se atentar, em um sentido mais amplo, para o estudo das características dos gêneros a partir da concepção bakhtiniana, "pela qual toda produção linguística deve ser entendida como uma forma de ação social, situada sócio-historicamente" (LOPES-ROSSI, 2006, p. 3).

Para tanto, Lopes-Rossi (2012, p. 148) sugere que o estudo dos gêneros discursivos deve obedecer às seguintes etapas a fim de que todas as propriedades referentes ao gênero sejam atingidas:

1) seleção de textos do gênero a ser estudado; 2) estudo de suas condições de produção e de circulação, do seu propósito comunicativo, das temáticas possíveis de serem abordadas, ou seja, de suas propriedades sociocomunicativas; 3) estudo das características do suporte típico do gênero e das possibilidades ou regularidades de ocorrência e posicionamento dos elementos composicionais verbais e não verbais; 4) análise das possibilidades de organização dos elementos verbais, especialmente da forma de desenvolvimento textual; 5) identificação das características 
linguísticas e de estilo, bem como de marcas enunciativas típicas do gênero. (LOPES-ROSSI, 2012, p. 148-9).

A partir dessas diretrizes e visando a contribuir com o trabalho didático de leitura e produção da quadra popular, passamos às características desse gênero discursivo.

\section{O gênero discursivo quadra popular}

Diante do exposto, segue a análise do gênero quadra popular, demarcando sua historicidade, suas condições de produção e circulação, seu propósito comunicativo, suas características temáticas e enunciativas, composicionais e estilísticas.

\section{Breve histórico do surgimento do gênero discursivo quadra}

A quadra, como poema marcado pela brevidade estrófica, não constitui uma particularidade exclusiva da inspiração poética brasileira. Outras culturas praticam-na, tendo como modelo de verso breve: dísticos, tercetos, quadras, sextilhas etc. Spina (2003, p. 110), reportando-se às estrofes das cantigas provençais, assevera que relativamente podem "oscilar (excluindo-se o refrão) entre dois ou dez versos; a quadra predomina: e a ela se segue o dístico (utilizado sobretudo nas composições paralelísticas); os trísticos e as sextilhas também são frequentes."

Zumthor (2010, p. 195) acentua que "onde quer que pratique a versificação em cesura, a poesia oral utiliza apenas um número limitado de formas estróficas de base, às vezes combinadas (em vez de fundidas) em unidades mais vastas". O autor acrescenta ainda que "o estudo das literaturas medievais mais antigas e dos folclores modernos permite remeter, em quase todos os casos, ao dístico, ao terceto, ou à quadra originais" (ZUMTHOR, 2010, p. 195). Nesse prisma, Zumthor (2010) ainda nos informa que "a própria quadra aparece, aqui e ali, menos como uma fórmula rítmica autônoma do que 
como o efeito de aglutinação de dois dísticos" (ZUMTHOR, 2010, p. 195). Spina (1982, p. 69) mostra-se conclusivo a esse respeito ao afirmar que "o dístico e a quadra são, portanto, as formas matrizes do raciocínio poético dos trovadores populares. Há quadras que não são mais que associação de dísticos."

Para Wanke (1973, p. 96), semelhantemente, "a menor estrofe é o dístico". E desse, conforme enfatiza o autor, a quadra teria nascido de duas maneiras, dobrando-se "o dístico, com objetivo de variar a rima. Assim, obtemos, no duplo dístico, rimas paralelas (aabb), alternadas (abab), abraçadas (abba), tipo rubai (aaba), tipo zéjel (aaab), monórimas (aaaa)" (WANKE, 1973, p. 96). Como modelo, Wanke (1973) apresenta-nos a célebre quadra que funciona como refrão e que, também, representa a segunda porta que marca a entrada latina de metrificação setissilábica.

Esse modelo heptassilábico formado de quatro versos aparece no poema Leonoreta na quadra com rima leonina, segundo Wanke (1974). O autor (WANKE, 1974, p. 78) destaca a importância dela por ter fixado "um antigo esquema rimático, já usado em latim, com rimas internas no $1^{\circ}$ verso do qual ainda hoje encontramos vestígios no trovário popular" (WANKE, 1974, p. 78). Essa quadra é de autoria de João Lobeira que fora "travador da corte de D. Dinis, de Portugal, entre 1258 a 1285, registrado no Cancioneiro da Biblioteca Nacional, antigo Colocci-Brancutti." (WANKE, 1973, p. 55-6):

$$
\begin{aligned}
& \text { Leonoreta, fin roseta, } \\
& \text { bela sobre toda fror, } \\
& \text { Leonoreta, nom me meta } \\
& \text { em tal coita vosso amor. }{ }^{1} \\
& \text { (WANKE, 1973, p. } 55-6) \text {. }
\end{aligned}
$$

A quadra pode geminar também do desdobramento de dois dísticos longos, transformando-os em quatro. Assim "quando temos dois versos muito longos, formados de hemistíquios, sua tendência natural é serem tratados como versos separados" (WANKE, 1973, p. 96). De acordo com o estudioso, o verso de sete sílabas tem sua origem latina e teria sido a primeira influência para a

\footnotetext{
${ }^{1}$ Tradução apresentada por Wanke (1974, p. 78): "Leonoreta, fina rosinha, bela acima de qualquer flor, Leonoreta não me ponha em tal tristeza vosso amor!".
} 
formação do setissilábico, melhor dizendo, "o setissilábico deve ter nascido do duplo tetrâmetro trocaico, ou seja, trocando em miúdos, do verso de dois tetrâmetros (duas vezes quatro sílabas) trocaicos (quer dizer, terminado em palavra paroxítona) o que dá em setissílabo grave" (WANKE, 1973, p. 97). Exemplifica o autor, apresentando-nos como modelo um pequeno trecho do hino latino (WANKE, 1973, p. 97): "Sicut pratum picturatur / et ver vernis floribus,// Mater dei figuratur / mysticis nominibus".

Wanke (1973, p. 97-98), referindo-se à quadra como trova setissilábica, diz que ela "na origem seria um dístico de quinze sílabas terminado sempre em versos agudos." Tal modelo encontra-se em Gil Vicente, tido por estudiosos como os vestígios de quadras "genuinamente populares" (WANKE, 1973, p. 98): "Já vedes minha partida, / os meus olhos já se vão.// Se se parte a minha vida / cá me fica o coração."

Spina (2003, p. 111-112) confirma essa tendência quando trata dos versos de uma cantiga provençal de Vasco Praga de Sandim. O Autor nos instrui ao dizer que "os hemistíquios $(7+8)$ formariam uma quadra". Para tanto, segue o modelo: "Cuidado vós, meu amigo, / ca vos non quer' eu mui gran bem, // e a mi nunca bem venha, / se eu vejo no mundo ren."

A brevidade, portanto, na forma do gênero poético oral, para Zumthor (2010), constitui uma convenção adotada por várias culturas, observada do Havaí à Irlanda e ao Ártico. O autor comenta que "entre os Santali, no leste da Índia, homens e mulheres improvisam, no final dos cantos rituais, poemas muito curtos, raramente com mais de seis versos" (ZUMTHOR, 2010, p. 147). Na África, especificamente, na Somália, segundo Zumthor (2010, p. 147), "surgiu, por volta de 1945, uma forma de canção de tema erótico ou político, encerrada em dois versos, o balwo."

Wanke (1973) atesta esse interesse pelas composições poéticas mais curtas ao sustentar que "na literatura oral, folclórica, nota-se uma nítida preferência pela quadra como forma estrófica" (WANKE, 1973, p. 27). Spina (2003, p. 101), de igual modo, assinala que "a canção provençal compunha-se de número variável de estrofes, oscilando entre cinco e sete, e terminando com 
uma, duas ou três tornadas", isto é, "estâncias mais curtas em número de versos em relação aos das estrofes" (SPINA, 2003, p. 103).

O aparecimento de rudimentos da quadra, em árabe, remete ao século IX, pois o povo "repetia poemas curtos cujo testemunho temos hoje na descoberta das carjas moçárabes" (WANKE, 1974, p. 78). A carja, em língua árabe, constitui uma das estrofes da muaxaua, um tipo de poema estrófico, "constituída, estruturalmente, de mote inicial, ou melhor, o prelúdio de dois versos rimados, seguido de estrofes em quintilha, dos quais os últimos versos rimam aa, bbbaa, ccaaa, etc., rematados pela carja, ou seja, uma estrofe em língua moçárabe" (WANKE, 1973, p. 89).

Essa forma poética é "sempre de poesia feminina, ou seja, feita para ser cantada por mulheres - exatamente como nas "cantigas de amigo" de época muito posterior" (WANKE, 1973, p. 90). O estudioso ainda adverte que "se trata de pequenos poemas populares, independentes, e conhecidos em toda parte" (p. 90). Transcreve-se abaixo, segundo citado por Wanke (1973, p. 90), um exemplo de carja interpretada pelo filósofo judeu-inglês Samuel Stern e por Canteras:

\author{
Que faré yo, o que serad de mibi? \\ Habibi, no te tolgas de mibi! \\ Que faré, mamma? \\ Meu I'habib es ad yanna! ${ }^{2}$ \\ (WANKE, 1973, p. 90).
}

Indícios da quadra, de acordo com Wanke (1974, p. 78), são verificáveis nos "Cancioneiros portugueses (Ajuda, Colocci-Brancutti, Vaticana) do século XIII". Observam-se, também, vestígios dela, nas "Cantigas de Santa Maria do rei-sábio de Castela e Leon, D. Afonso X, elas aparecem, em galego-português, como refrão" (WANKE, 1974, p. 77). A quadra, desse modo, funcionava como estribilho nas cantigas. $O$ estribilho ou refrão, mais comumente nas canções populares como em outros poemas, segundo destaca Staiger (1972, p. 34), se

\footnotetext{
2 Tradução apresentada por Wanke (1973, p. 90): "Que farei eu, que será de mim? Meu amigo, não te vás do meu lado! Que farei, mamãe? O meu amigo está à porta!".
} 
diferenciava do restante da produção pelo "seu caráter musical". Pois o refrão, centrando em si o lirismo, é o que fazia todo o poema "conservar-se liricamente coeso" (STAIGER, 1972, p. 35).

Moisés (1973, p. 102), distinguindo a canção popular da erudita, salienta que o berço natal dessa canção foi a Provença, e "o trovador Giraud de Borneil (1165-1199), o primeiro que the emprestou a estrutura fundamental no século XI." Posteriormente, difundiu-se para a Península Ibérica, o Norte da França, a Inglaterra e a Itália. Vale ressaltar ainda que, para Moisés (1973, p. 102), "a poesia dos travadores havia promovido a aliança medular entre a letra do poema e o som, de modo que não se concebia a poesia separada da instrumentalização e do canto (daí o designativo canção, cantiga, cantar)."

Segundo consta em Wanke (1974, p. 78), a quadra também "aparece no Cancioneiro de Baena, espanhol, encabeçando um tipo poemático chamado "cantiga"'". Sua incidência continua séculos adentro. No século XV e XVI, a cantiga, com oito ou dez versos versados nos moldes da quadra, "domina o Cancioneiro geral de Rezende, publicado em 1516 por D. Manoel o Venturoso" (WANKE, 1974, p. 78). No século XIX, elucida Wanke (1974, p. 84) que nos anos de 1829, Almeida Garrett, "tinha ele vinte e tantas trovas (não a nossa quadra, pois ela não se chamava trova) e romances populares, xácaras e solaus."

\section{O surgimento do nome trova referindo-se à quadra}

A denominação trova só muito depois foi atribuída, mais especificamente, à quadra. Wanke (1973, p. 20) menciona que, em Portugal, "a primeira vez que vimos a palavra "trova" ser utilizada no sentido moderno foi em... Camões." Segundo o estudioso (1974), na peça Auto dos Enfatriões, Camões, naquela ocasião, havia intitulado com o nome trova a "seguinte quadra, que serve de "cabeça" a uma antiga cantiga composta por um dos personagens da peça" (WANKE, 1974, p. 142). Como exemplo, citamo-la: 
Coração de carne crua,

Ve-lo teu amor aqui,

Que esmorecido por ti

Jaz no meio desta rua.

(WANKE, 1974, p. 142).

Todavia, vale frisar que a quadra, apesar de receber pela primeira vez o nome "trova", faz lembrar-nos de que ainda funcionava como parte de uma composição maior, visto que reporta a uma prática muito comum usada culturalmente ao longo dos séculos:

\begin{abstract}
Nos primeiros tempos da língua (séculos XII ou XIII), encontramo-la sendo chamada de "refran". Até o século XV, era a estrofe inicial de um tipo poemático chamado "Cantiga". Depois que a "moda" italiana, no século XVI, invadiu Portugal, passou a se chamar "cantar velho" e (segundo Carolina Michaëllis de Vasconcelos) "cantarcico" ou "cantarcilho". No século XVIII, era às vezes, apresentado isoladamente, sob o nome de "mote". Também "quarteto". Bocage tem muitos Epigramas em trova, o que designava mais o conteúdo que a forma. (WANKE, 1973, p. 20).
\end{abstract}

Para Wanke (1973, p. 18), "a palavra trova já designou e ainda designa outras coisas que não a quadra em redondilha maior", isto é, a quadra em versos heptassilábicos. De acordo com seus estudos, a trova fora "introduzida no português através do provençal (occitânico) troba, significando o poema, a composição de qualquer metro ou número de versos e estrofes" (WANKE, 1973, p. 18-19). O autor (WANKE, 1973) esclarece ainda que a troba tenha, provavelmente, sido originada do tropo. 0 tropo se referiria, enquanto termo do latim bárbaro, consoante acentua Wanke (1973, p. 19), a "texto literário e musical introduzidos em peça literária."

Reportando-se à Idade Média, de acordo com Wanke (1973), neste período, devido à importância do trovadorismo medieval, a palavra trova é fixada pelos poetas trovadores designando toda produção poética independente ou poema. Melhor dizendo, mais especificamente, nas palavras do autor, a trova "aparecia como a designação geralmente dada ao "produto poético" ou "poema"'"' (WANKE, 1973, p. 19). 
Desse modo, a irradiação do nome trova cognominando a quadra como tal, para Wanke (1974), antes da publicação, em 1903, de Mil trovas populares portuguesas, de autoria conjunta de Agostinho de Campos e Alberto de Oliveira, é vista como "totalmente eventual" (WANKE, 1974, p. 142). Posteriormente, entretanto, Trovas de Espanha, do Conde de Afonso Celso, em 1904, é a obra que "introduz o termo com esta acepção, no Brasil" (WANKE, 1974, p. 142). Em 1907, os estudantes Carlos Estevam, Manoel Monteiro, A. Silveira Carvalho, Moreira Cardoso, Ademar Tavares lançam, em Recife, Descantes, em que "a palavra trova aparece em uma das quadras dedicada a Carlos Estevam por Adelmar Tavares" (WANKE, 1974, p. 145). Portanto, conforme enfatiza Wanke (1974, p. 145), "a nova nomenclatura estava definitivamente implantada, especialmente no Rio de Janeiro, para onde Ademar Tavares se mudara" e "publicava seu segundo livro, Trovas $e$ trovadores (1910)".

\section{A definição do gênero discursivo quadra também chamada quadrinha}

Como já amplamente delineado, pode-se inferir que junto à popularização da quadra denominada trova vinculou-se uma rica variedade de designações, tanto se referindo a nomes quanto a formas compositivas. Essa falta de precisão quanto à nomenclatura, ainda hoje, faz-se notória, principalmente nas definições confusas dos dicionários.

No Aurélio (FERREIRA, 2001, p. 570) de Língua Portuguesa, por exemplo, a quadra recebe a seguinte acepção: "estrofe de quatro versos; quarteto, copla." Para trova, o mesmo dicionário (FERREIRA, 2001, p. 690) traz as acepções: "1. Composição lírica ligeira e mais ou menos popular. 2. Quadra de tom popular." Vale destacar que, para quadrinha, o Aurélio não apresenta nenhuma definição. O dicionário Scottini define a quadrinha como "trova popular com quatro versos, quadra, trova" (SCOTTINI, 2009, p. 444). A trova, para este dicionário, trata-se de "canção, conjunto de quatro versos, poemas" 
(SCOTTINI, 2009, p. 536). Entretanto, no que se refere à quadra, não apresenta sequer uma acepção.

Moisés (1973, p. 87), todavia, denomina a quadra como quadrinha, definindo-a como uma composição formada por "quatro versos, caracterizados pela concisão, ligeireza, condensação do pensamento poético; típica da poesia popular". Constituindo uma forma que, segundo o estudioso, também "continua a ser muito cultivada, inclusive por um poeta marcantemente racionalista como Fernando Pessoa". De modo similar, Goldstein (2004, p. 43) entende a quadrinha como "um poema de quatro versos que, geralmente, desenvolve um conceito relativo à filosofia popular".

Como visto, pode-se deduzir que a nominação "quadra" ou "quadrinha" constitui dois modos de se referir a uma mesma produção poética. Tal fato torna-se evidente quando Wanke (1973, p. 20) nos informa que, "em Portugal, a designação comum é a de "quadra", também ouvida no Brasil." Entretanto, o estudioso nos alerta que, no Brasil, a outra nominação concorrente à quadra seria a "quadrinha", a qual "também é usadíssimo" (WANKE, 1973, p. 20).

Amaral (1976), incluindo a quadra no tronco da poesia popular, diz que ela encontra-se melhor representada no ramo da poesia rústica, dividindo-se esta em tradicional e inventiva. Assim referindo-se à poesia tradicional nos avisa que ela se compõe "principalmente de quadras soltas, de romances e xácaras;" e que, como conservação no molde português, neste gênero, "as quadras soltas, em setissílabos" constituem os "melhores exemplos" (AMARAL, 1976, p. 102). À guisa de modelo, eis uma quadra portuguesa:

\footnotetext{
A roseira com suas rosas, toda se humilha ao chão; quando a roseira se humilha, que fará meu coração! (AMARAL, 1976, p. 164).
}

A disposição estrófica da quadra brasileira se acha fundida no molde da quadra portuguesa, composta de quatro versos com rimas alternadas (abcb) (AMARAL, 1976). Esse verso de sete sílabas, heptassílabo ou redondinho maior, 
para Goldstein (2004, p. 27), "é o mais simples, do ponto de vista das leis métricas", provavelmente, por isso, conforme realça a autora, "seja o verso predominante nas quadrinhas e canções populares". Spina (2003, p. 30) atesta nos informando que "o redondilho maior, talvez, por ter sido desde o seu nascimento o metro por excelência da poesia popular, conseguiu todavia manter em todos os tempos a sua continuidade."

A cadência rítmica dos versos, conforme acentua Amaral (1976, p. 170), "está inteiramente subordinado às pausas, cadências e balanços da dança." Para Goldstein (2004, p. 13), a regularidade e simetria comum à quadra, assim como a cadência infiltrada nos versos, se dão pela incorporação do ritmo da "vida que as pessoas levavam", modelo que "prevaleceu até fins do século passado e início deste" (GOLDSTEIN, 2004, p. 13).

\section{Distinção da quadra popular da quadra literária}

Cavalheiro (1989, p. 15) nos comunica que "a quadra dita popular obedece geralmente ao esquema $A B C B$, de rimas simples: rimam somente $02^{\circ}$ com o 40 versos". A autora, ao se referir aos poetas populares como os cantadores e violeiros e os autores de literatura de cordel, destaca que "suas composições se aproximam mais do folclore propriamente dito e, de certa forma, mais do trovadorismo medieval, por ser mensageira, contar uma história ou avisar de alguma coisa" (CAVALHEIRO, 1989, p. 11). Cascudo (2010, p. 93) nos certifica que "os quatro pés eram a quadra, de sete sílabas, a mais antiga forma do desafio sertanejo."

Para Cavalheiro (1989, p. 15), a diferença entre a trova popular e a trova literária é que esta é "exercida habitualmente por poetas de maior requinte na arte de trovar e tem, no geral, os quatro versos rimados." A autora salienta que "pessoalmente, como frisamos, preferimos o esquema $A B A B$ (rimados $1^{\circ}$ com $3^{\circ}$ e o $2^{\circ}$ com $04^{\circ}$ )." Essa escolha constitui, entre esses trovistas, um "aprimoramento da trova", justificando que "a grande preferência 
é pelas rimas duplas $A B A B$, chamadas cruzadas, entrelaçadas, alternadas, intercaladas" (CAVALHEIRO, 1989, p. 15).

Essa diferença teve seu marco, segundo Cavalheiro (1989, p. 12), quando "em 12.8.66, Luiz Otávio fundou a União Brasileira de Trovadores UBE, voltada para a quadra literária, com sede na então Guanabara, hoje, Rio de Janeiro." A autora ainda nos informa que "A UBT ramificou-se por todo o território nacional, com a fundação de Delegacias e Seções, sempre a promover concursos de trovas e Jogos Florais."

Wanke (1976, p. 9) considera a trova como "a quadra setissilábica autônoma." Para o autor, "a trova popular é a folclórica, a popularizada, a que anda na boca do povo". A literária, entretanto, o autor a define como a que "é produzida por alguém no objetivo de fazer obra de arte, humorismo, filosofia, propaganda, fixar algum conceito didático, etc. Pode se popularizar ou não." Exemplificando, citamos uma das trovas literárias de Luiz Otávio:

\author{
Beijos de mãe... filha... esposa... \\ Tantos beijos ganha a gente! \\ - Como pode a mesma coisa \\ ter sabor tão diferente? \\ (FERNANDES, 1972, p. 145).
}

\title{
Produção, circulação e o propósito das quadras populares
}

A alma do povo seria o dínamo de onde descarrega essa força poética. Para Amaral (1976, p. 144), "toda a literatura popular do Brasil provém do tronco português." Pois, de acordo com o autor:

Deriva dessa velha corrente, que domina todo o país e de acordo com o crescente esquecimento dos seus productos e com a crescente adaptação do brasileiro ao ambiente físico e social próprio, se têm vindo formando centros de elaboração locais e regionais, manifestos em certas tonalidades gerais, nos reflexos da natureza, dos costumes, da vida econômica, na organização de novos ciclos temáticos, etc. Essas formações esboçam, naturalmente, os primeiros lineamentos de uma geografia social e psicológica do Brasil popular (AMARAL, 1976, p. 145). 
Desse modo o povo, tal como evidencia Amaral (1976), com base em substratos depositados no inconsciente coletivo, desde o período colonial, atua criando e recriando vivamente. Para Amaral (1976, p. 148), a alma coletiva "atua na evolução da nossa poesia popular, toda de origem portuguesa mediata e imediata, imprimindo-Ihe feições nacionais." Porquanto, consoante destaca o autor (AMARAL, 1976, p. 145), este "fundo recebido do outro lado do Atlântico, em pequena parte, se conserva tal qual, com insignificantes modificações." Cascudo (2010, p. 104) certifica isso se referindo às cantorias dos repentistas nordestinos, ao dizer-nos que "o que existe no sertão, evidentemente, nos veio pela colonização portuguesa e foi modificando para melhor. Aqui tomou aspectos novos, desdobrou os gêneros poéticos, barbarizou-se, ficando mais áspero, agressivo e viril." Em suma, enfatiza o estudioso que "o fio vinculador é lusitano" (CASCUDO, 2010, p. 104).

Andrade (1976, p. 81), estudando a música popular nacional, ressalta que as influências portuguesas "permanecem mais facilmente reconhecíveis é nas cantigas-de-roda infantis do Brasil". Para tanto, ao estudar a cantiga de roda "Ciranda", esclarece-nos que, no Brasil, separada do ramo de estrofes que a formavam, ela é "roda exclusivamente infantil e geralmente cantada com uma estrofe só e refrão" (ANDRADE, 1976, p. 92).

A apropriação dessa quadra se dá por um processo de afeiçoamento "à nossa psicologia étnica" (ANDRADE, 1976, p. 92). De tal modo que, "a melodia brasileira parece apresentar uma seleção discrecionária de elementos melódicos." Razão essa que, segundo adverte Andrade (1976), parece se justificar pelo fato de a "Ciranda" apresentar "um processo de escolha, aceitação, desbastamento, deformação, que transforma fontes exclusivamente estrangeiras numa organização que sem ser propriamente original, já é necessariamente nacional" (ANDRADE, 1976, p. 93). Para tanto, veja versão nacional da "Ciranda": 
volta e meia vamos dar.

(ANDRADE, 1976, p. 92).

De acordo com Amaral (1976), as vertentes tradicionais e inventivas da poesia popular se manifestam de modo expressivo distintamente através do canto e da recitação. Assim, segundo Amaral (1976, p. 69), "há versos feitos para serem cantados à viola ou ao violão; há versos que apenas se declamam: são décimas, são orações, são fábulas, são parlendas". No entanto, importa frisar que, num caso como noutro, são modos de versar que se apoiam na forma da quadra popular. Em todo caso, quanto ao cancioneiro do campo, isto é, a poesia do campo, o autor nos comunica que:

[...] quase toda ela se reparte em dois grandes esgalhos: um, o das composições devidas em tudo à inventiva dos poetas da roça e geralmente constantes de várias estâncias - quadras, sextilhas, oitavas, - em versos de cinco ou sete sílabas, mais comumente de sete; outro, o das quadras soltas e anónimas, em redondilha, pela maior parte de origem portuguesa, modificadas pela colaboração inconsciente dos cantadores. No primeiro caso, MODA; no segundo, TROVA, ou, como diz geralmente o povo, verso (aliás bérso) (AMARAL, 1976, p. 70).

Para Amaral (1976, p. 35"), "esses versos estão, ordinariamente, de tal modo entrelaçados com a música, ou com a música e a dança, que não se pode distinguir qual é o principal dos três elementos, qual é o acessório." Pois, para o autor, "todos podem ser principais e acessórios, alternativamente." Toda a poesia desse cancioneiro, de acordo com Amaral (1976, p. 70), constitui "a poesia dos tropeiros, dos carreiros, dos boeiros, dos trabalhadores de roça. É a poesia dos fandangos, das noites de São João em roda das fogueiras, dos puxirões e bandeiras do Divino, dos responsos e dos pagodes."

Como modelo, segue uma das quadras de Moda Caipira recolhida por Andrade (1987, p. 164):

Morena, minha morena de ti num posso isquecê, tua boca é tão mimosa qui mi faiz inloquecê. (ANDRADE, 1987, p. 164). 
O primeiro verso desta quadra atua como molde conservado da quadra portuguesa, mas com diç̧ão e feição nacional. Amaral $(1976$, p. 83) acrescenta que "a trova popular de S. Paulo, e portanto do Brasil, não é senão uma lenta evolução da trova popular portuguesa, quando não é a própria trova popular portuguesa conservada com ligeiríssima alterações." Esse genuíno abrasileiramento com que o poeta da roça molda a trova popular portuguesa é vista como um sinal de que "a nossa obra tem sido mais de nacionalização do que de criação" (AMARAL, 1976, p. 83). Além do mais, "o caipira é que principalmente as conserva; do meio do caipira é que, em regra, elas extravasam" (AMARAL, 1976, p. 79).

Assim, a quadra popular espelha as várias atividades coletivas das zonas rurais, pois está entranhada "nos costumes, faz parte de vários atos coletivos usuais" (AMARAL, 1976, p. 166). Eis duas versões brasileiras representantes da maneira como a arte incorpora expressivamente a vida: a primeira de São José do Rio Pardo-SP e, a segunda, de Tremembé-SP, colhidas por Amaral (1976, p. 159):

\footnotetext{
Valha-me Nossa Senhora, Santo Antonio de Nazaré. A vaca mansa dá leite, a braba dá quando qué. (AMARAL, 1976, p. 159).

Eu queria ser peneira na colheita do café, para andar dependeurado na cintura das muié. (AMARAL, 1976, p. 159).
}

Como visto, pode-se dizer que as quadras populares se articulam vinculadas à vida do homem do campo, sobretudo, nas relações representadas por suas manifestações simbólicas social e religiosamente vivenciadas. Pois, conforme salienta Brandão (1985, apud TEIXEIRA, 2012, p. 22), "uma análise do sistema que envolve os rituais populares se dá na configuração das relações e representações sociais onde se combinam e, às vezes, se enfrentam o 
simbólico e o social, a festa e a rotina, os personagens do folguedo e os sujeitos do cotidiano da sociedade promotora."

Essa tradição não se encontra de tudo desaparecida na atualidade. Elas, aliás, mantêm-se vivas. A presença da quadra observa-se na manutenção das composições que tradicionalmente são mantidas pelas manifestações de vários tipos de folguedos como moçambiques, congadas, bumba-meu-boi, etc. Exemplificando, apresenta-se a seguir o depoimento de Mestre Paizinho, cedido em 7/12/2014, via facebook. Para esclarecimento, vale frisar que Geraldo de Paula Santana é conhecido como Mestre Paizinho da Companhia de Moçambique Unidos de São Benedito do Parque Bandeirante, localizado no Município de Taubaté, no Vale do Paraíba:

Bom dia estimado amigo. A manifestacao esta sempre presente, os versos vem da oralidade com intuito de valorizar o passado, dar luz ao presente e enriquecer o futuro. Publico alvo todas as idades.Temos mtos materias em jornais ver no google Mestre Paizinho. no youtb tem varios videos de apres com rimas $e$ no site mestrepaizinho.com.br. Na revista globo rural ver congada a danca da liberdade. Abraco

De acordo com Teixeira (2012), em estudo sobre a Congada e o Moçambique do Vale do Paraíba, nos informa sobre Mestre Paizinho que "atualmente, sua companhia tem um total de 22 integrantes. Além disso, ele também repassa seus conhecimentos sobre moçambique e cultura popular para crianças e adolescentes em escolas municipais de Taubaté" (TEIXEIRA, 2012, p. 50). Para tanto segue algumas quadras das "canções do moçambique" cedidas por Mestre Paizinho, enviadas via facebook, em 15/12/214. Mestre Paizinho nos declara que "a musicalidade do moçambique se torna forte quando traz a rima, origem dos africanos que faziam com muito amor...". Assim temos:

\footnotetext{
A dança do moçambique,

é bonita demais,

é cultura africana,

não esqueço jamais

Que chegada tão bonita, nós fizemos nesta hora, que chegou S. Benedito,
} 
e a Virgem N. Senhora.

Do pai passou pro filho, e o filho continuou, o nosso moçambique, Mestre Paizinho que ensinou.

O moçambique é uma escola, eu quero te ensinar, olha o ritmo da musica, é só você acompanhar.

Outra manifestação da quadra que se faz observar, atualmente, é a presença dela na Toada. Para Cascudo (apud SANTOS NETO; RIBEIRO, 2011, p. 22), "outra forma de romance lírico brasileiro é a toada, canção breve, em geral de estrofe e refrão, em quadras." Para tanto segue o refrão da Toada do Bumba-meu-boi da Fé em Deus, do Estado do Maranhão. A autoria e a interpretação são de José da Conceição Silva (Zezinho), conforme apontado nos estudos de Santos Neto e Ribeiro (2011, p. 63):

\author{
A festa de bumba-boi \\ é melhor do Maranhão \\ Sotaque de Guimarães \\ que mantém sua tradição. \\ (SANTOS NETO; RIBEIRO, 2011, p. 63).
}

Outra fonte em que se nota o emprego da quadra é na dança Meiacanha rio-grandense, vigorando ainda em nossos dias. Conforme Cortês e Lessa (1955, p. 74), nessa dança, "o rapaz oferece à sua companheira uma quadrinha", cujo modelo se pode ver a seguir:

\author{
Moça: \\ $\mathrm{O}$ anel que tu me deste \\ Era vidro e quebrou; \\ $\mathrm{O}$ amor que tu me tinhas \\ Era pouco e se acabou. \\ Rapaz: \\ É que o amor que eu te tinha \\ Não era pra eu te tê; \\ $\mathrm{E} o$ amor que tu me tinhas \\ Não era pra tu me tê! \\ (CORTÊS; LESSA, 1955, p. 77)
}


Não somos uma nação exclusivamente católica, mas marcada pelo sincretismo religioso. Para tanto, segue modelo de melodias de Catimbó em quadra, coletada por Mário de Andrade:

\author{
Tabatinga foi prá mata, \\ Ele foi fazê feitiço, \\ Tabatinga, óia lá, \\ Tabatinga, cuida nisso! \\ (ANDRADE, 1963, p. 80)
}

Spina (1982, p. 14) ressalta que "a poesia no seu estágio primitivo não é, portanto, exclusivamente ritual." Para ele, junto a essa poesia tradicionalmente coletiva, "intimamente ligada aos rituais mágico-religiosos da comunidade, pratica-se uma poesia circunstancial, que versa os temas mais variados, sobretudo profanos, de amor, de guerra, de recordações de fatos da vida diária, de sátira aos viajantes estrangeiros." Exemplificando um fato cotidiano de nosso tempo, segue a quadra solta:

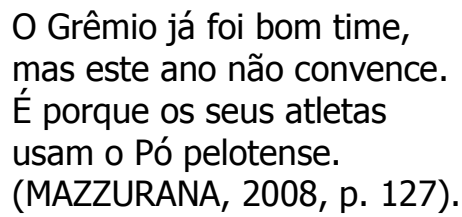

\title{
A caracterização da quadra popular de molde português
}

Os temas e os elementos composicionais, de acordo com Bakhtin (2011), configuram como unidades integrantes dos gêneros discursivos, determinando, consequentemente, a materialidade de sua forma de acabamento.

Desse modo, estabelecendo relação temática do contexto com os aspectos composicionais, valha-nos saber que nas quadras populares tradicionais com influência portuguesa os temas são bem variados. Uma dessas variedades temáticas, de acordo com Amaral (1976), é percebida com a presença da flora portuguesa na trova brasileira. Ela se dá por meio de nomes de flores e plantas como o do cravo e o da rosa. Completando esse simbolismo, aparece "a açucena, o amor-perfeito, a perpétua, a manjerona, o alecrim, o 
manjericão, a arruda, a salsa etc., que a cada momento ocorrem nos versos de cá e de lá" (AMARAL, 1976, p. 157).

Exemplificando, veja modelos coletados de Amaral (1976, p. 138), de Wanke (1974, p. 338), de Mazzurana (2008, p. 30 e 43) certificando essa diversidade temática com base na flora, especificamente:

Rosa branca, toma cor, não sejas tão desmaiada, que dizem as outras rosas: Rosa branca, não és nada. (AMARAL, 1976, p. 138).
Alecrim verde se chama uma esperança perdida. Quem não goza o que deseja, mais antes perder a vida. (MAZZURANA, 2008, p. 43).
Batatinha quando nasce deita rama pelo chão. A menina quando dorme põe a mão no coração. (WANKE, 1974, p. 338).

Outros temas bastantes presentes nas quadras populares tradicionais referem-se ao amor, ao casamento, às mulheres. Para Amaral (1976, p. 155), esses, "naturalmente, em grande número, são os temas das quadras mais graciosas e das mais belas". Seguem modelos de quadras portuguesas retiradas de Amaral (1976, p. 82) e de Wanke (1974, p. 92), acompanhadas de quadras brasileiras colhidas por Mazzurana (2008, p. 179):

Já te dei meu coração e sua chave de abrir; não tenho mais que lhe dar, nem você o que pedir. (AMARAL, 1976, p. 82).

Açucena quando nasce toma conta do jardim; também ando procurando quem tome conta de mim. (MAZZURANA, 2008, p. 30).
O amor nasce da vista e mora no coração. Vive da correspondência e morre da ingratidão. (WANKE, 1974, p. 92).

Eu sou cravo e tu és Rosa, qual de nós brilhará mais? Os cravos pelas janelas, as rosas pelos quintais. (AMARAL, 1976, p. 138).
Seremos felizes na vida quando chegar a decisão. As flores enfeitando nosso lar e os beijos, a nossa união. (MAZZURANA, 2008, p. 179).

Amaral (1976) nos faz saber que há também "temas truanescos", palhaçadas recheadas de gabolices, pilhérias as mais fantásticas, onde reina a sátira escarnecedora dos ricos orgulhosos, dos vadios preguiçosos, dos maus sacerdotes, das mulheres de comportamento desregrado, etc. Para tanto, segue exemplo retirado de Wanke (1974, p. 100): 
Paulista de Taubaté, cavalo pangaré

e mulher que mija em pé,

libera nos Dominé!

\section{Variações brasileiras de quadras populares nos moldes da quadra portuguesa}

Essas reminiscências de elementos da cultura portuguesa são perceptíveis na maneira como é configurada a linguagem da poesia popular brasileira. Isso se percebe pela presença de elementos linguísticos estranhos ao linguajar do homem do campo. Quanto a essa adaptação linguística, Amaral (1976, p. 149) anuncia que ela "actua, antes de mais, pela linguagem. Os versos importados têm de sofrer logo uma primeira adaptação à fonética, à morfologia e à sintaxe dialectais". Para fins de elucidação, seguem as quadras 1, 2, 3 de origem portuguesa, e a 4 brasileira, retiradas de Amaral (1976):

1

Inda que o lume se apague, na cinza fica o calor; inda que $o$ amor se acabe, no coração fica a dor. (AMARAL, 1976, p. 149).

3

Pinheiro, dá-me uma pinha, pinheiro, dá-me um botão; menina, dá-me os teus olhos que eu te dou meu coração. (AMARAL, 1976, p. 150).
2

Já te quis bem nesta vida, já te perdi a afeição, já te varri à vassoira de dentro do coração. (AMARAL, 1976, p. 149).

4

Pinheiro, me dê uma pinha, pinheiro, me dê um botão; morena, me dê um abraço, que te dou meu coração. (AMARAL, 1976, p. 150).

Na quadra 1, conforme acentua Amaral (1976, p. 149), a palavra "lume" não constitui vocábulo comum no acervo linguístico do homem do campo, por isso a inteligência inventiva e reparadora optará pela substituição dela por "fogo". Outro aspecto observado por Amaral (1976), no caso da quadra 2, refere-se ao ditongo "oi", na expressão "varri à vassoira", o qual é trocado por 
"ou". Amaral (1976, p. 149) nos cientifica que o povo, em São Paulo, "conserve os dois ditongos, nunca usa um pelo outro nos mesmos vocábulos."

Na quadra 3, a força impositiva do pronome de segunda pessoa sofre abrandamento psicológico ao ser substituído pelo pronome de terceira como se observa na quadra 4. Andrade (1976, p. 91), analisando quadra com semelhante mudança, enfatiza a existente "distinção de psicologia étnica entre o português e o brasileiro, é que à maior franqueza impositiva do português substituímos uma delicadeza mais mole."

Em sociedades como a nossa, pensar a cultura, segundo Bhabha (1998), é pensá-la como um lugar fronteiriço, no qual "exige um encontro com o novo" (BHABHA, 1998, p. 27). Essa zona fronteiriça, para Franco Junior (1996), constitui o lugar da cultura intermediária. Pois esta é aglutinadora de diversos polos culturais, constitutivos dos mais diversos resíduos, tanto de culturas mais recentes como de velhas culturas, moventes ainda no magma vivo das representações do inconsciente coletivo.

Para Amaral (1976, p. 162), o indivíduo que compõe as quadras populares com base no molde português recorre, sob essa condição, "a regra, por muito que invente, ou pense inventar, não faz muito senão procurar inconscientemente na sua memória os ritmos, os ecos, as imagens, as palavras, as combinações de sílabas, os mil resíduos de emoção, de fundo e forma."

Andrade (1944 apud SOUZA, 2003), referindo-se a esse mecanismo de composição, cujo fenômeno se encontra nos improvisos dos cantadores nordestinos, avisa-nos que esses cantadores fazem uso do princípio da variação, a qual, por sua vez, consiste em "desnivelar a melodia tornando-a bem simples pra que ela se fixasse na memória. Mas depois de fixada em seu esquema inicial, o cantador se esmerava de novo em elevá-la de nível, individualizá-la em variações dum legitimo canto 'hot'"' (ANDRADE apud SOUZA, 2003, p. 23-4).

Esse fenômeno em que se dá o princípio da variação é encontrado, também, como legado da narrativa oral na escrita da Grécia Antiga e do Norte da Europa. Scholes e Kellogg (1977), apoiando-se nos estudos de Milman Parry 
sobre a poesia heroica composta oralmente, nos notifica que ela tem uma dicção fortemente poética e com alto teor formular. Segundo o autor, isso constitui:

[...] prova de composição oral, passou a demonstrar que os poetas orais não compõem senão mediante fórmulas. Eles improvisam, usando fórmulas convencionais em sua tradição poética como base para formar versos métrica e semanticamente adequados (SCHOLES; KELLOGG, 1977, p. 13-14).

Assim, pode-se dissertar que o processo dinâmico e dinamizador da quadra tradicional brasileira segue mecanismo de irradiação semelhante. Quanto a isso, assevera-nos Amaral (1976) que o poder gerativo calca-se nas "muletas iniciais" e nos "chavões" com que "o povo costuma começar as suas trovas avulsas, e que têm por efeito facilitar a composição e memorização. Essas muletas, que não são muito numerosas, têm um poder infinito de reprodução com variações" (AMARAL, 1976, p. 162). Demonstrando, temos: "Minha gente, venham vêr..., Eu fui aquele que disse..., Menina, minha menina..., Vamos dar a despedida..., Fui andando p'r um caminho...." (AMARAL, 1976, p. 163). Outras mais: "Atirei um limão verde..., Vai-te carta venturosa..., Ninguém viu o que eu vi hoje..., "Quem me dera ser um cravo..., Açucena co' pé na água..., Batatinha quando nasce...".

O autor acrescenta que esse processo inventivo não se dá apenas nos versos iniciais, mas também nos finais, apresentando, portanto, poucas transformações (AMARAL, 1976). Assim o verso inicial: "Menina, minha menina" muda-se para as formas: "Maria, minha Maria, Morena, minha morena, Menina da saia branca, menina dos olhos verdes" (AMARAL, 1976, p. 163). A forma: "Quem me dera ser um cravo" é tipo de numerosos versos em que a mesma ideia aparece com outras palavras, como se pode ver em: "Eu queria ser um lenço, Quisera ser como a rosa". Transformações semelhantes se notam no verso: "Atirei um limão verde", o qual, entretanto, tem, segundo Amaral, larga irmandade: "Atirei o limão doce, Atirei o cravo na água, Eu pinchei o anzol na água...". 
Um dos moldes comuns a essas quadras, segundo Amaral (1976, p. 165), é que elas se apoiam na variação em que "nos dois primeiros versos, enuncia-se um fato; nos outros dois, tira-se uma ilação, começando por "quando", repetindo o verso da primeira sentença, e terminando com exclamativa: "que fará...!". Assim, exemplificando, seguem os modelos 1 e 2 (Port. e Brasil), 3 (Barueri/SP) e 4 (Casa Branca/SP), retirados de Amaral (1976). Os modelos 5 (Pernambuco/PE), 6 (Port. e Brasil), 7 (Folclore goiano), 8 (Port.) e 9 (Cantigas Alentejanas/Port.), de Wanke (1974). E 10, 11 e 12, de Mazzurana (2008):

1

Fui ao mato cortar lenha, Santo Antônio me chamou: quando o santo chama a gente, que fará quem já pecou! (AMARAL, 1976, p. 164).
2

A roseira com suas rosas, toda se humilha no chão: quando a roseira se humilha, que fará meu coração. (AMARAL, 1976, p. 164).
3

Fui andando p'lo caminho, ramo verde me pegou, - Não me pegue, ramo verde, nosso amor já se acabou. (AMARAL, 1976, p. 165).
4

Cajueiro pequenino deita rama pelo chão; meu amor quando se deita põe a mão no coração. (WANKE, 1974, p. 383).

7

Minha gente, venham ver coisa que nunca se viu: minha gata pôs um ovo, minha galinha pariu. (WANKE, 1974, p. 395).

10

Lá atrás daquele morro tem um pé de maravilha. Estou falando com o velho, meu sentido está na filha. (MAZZURANA, 2008, p. 95).

\section{5}

A amora nasce da silva, a silva nasce do chão. A vista nasce dos olhos, o amor do coração. (WANKE, 1974, p. 392).

\section{6}

U fogo nasci da lenha, a lenha nasce do chão, o amor nasce dos olhos, vai vive no coração.

(WANKE, 1974, p. 393).
8

Minha gente, venham vêr Atrás do mar, está um rio, coisa que nunca se viu: aeroplano anda no ar, telegrama anda no fio. (AMARAL, 1976, p. 161).
Atrás de um rio, um regato, Atrás de um amor, vem outro, não há nada mais barato. (WANKE, 1974, p.392).

\section{Conclusão}

11

Fui na fonte beber água um bichinho me mordeu. Eu não sei que bicho é esse, mas que tanto me doeu! (MAZZURANA, 2008, p. 85).
12

Roseira, dá-me uma rosa, Cravina, dá-me um botão, Menina, me dá um abraço, que te dou meu coração. (MAZZURANA, 2008, p. 148). 
Os resultados mostram que a quadra popular no Brasil é um gênero discursivo que se caracteriza por ser plasmado no molde português, cujo afeiçoamento se dá por um processo formular, apoiado no princípio da variação. Conservando por "muletas iniciais", "finais" ou "chavões", muitas temáticas de origem, mas com adaptações já nacionalizadas.

Em suma, conclui-se que essas características do gênero discursivo quadra popular no Brasil podem subsidiar um trabalho de leitura e produção escrita em sala de aula nos Ensinos Fundamental e Médio.

\section{Referência}

AMARAL, Amadeu. Tradições populares. 2. ed. São Paulo: Hucitec, 1976.

ANDRADE, Mario. As melodias do boi e outras peças. São Paulo: Duas Cidades, 1987.

ANDRADE, Mario. Música de feitiçaria no Brasil. São Paulo: Martins, 1963.

ANDRADE, Mario. Música, doce música. 2. ed. São Paulo: Martins, 1976.

BAKHTIN, Mikhail M. Estética da criação verbal. Tradução de Paulo Bezerra. 6. ed. São Paulo: Martins Fontes, 2011.

BHABHA, Homi K. O local da cultura. Belo Horizonte: Editora UFMG, 1998.

BRASIL. Secretaria de Educação Fundamental. Parâmetros curriculares nacionais. terceiro e quarto ciclos do ensino fundamental: língua portuguesa. Brasília: MEC/SEF, 1998.

CASCUDO, Luis da Camara. Vaqueiros e cantadores, para jovens. São Paulo: Editora Gaia, 2010.

CAVALHEIRO, Maria Thereza. Segredos do bom trovar. como fazer trova, exemplos práticos, antologia. São Paulo: João Scortecci, 1989.

CORTÊS, Paixão; LESSA, Barbosa. Manual de danças gaúchas. 5. ed. São Paulo: Irmão do Vitale Editores, 1955.

FERNANDES, Aparício. A trova no Brasil. Rio de Janeiro: Artenova, 1972.

FERREIRA, Aurélio Buarque de Holanda. Minidicionário século XXI escolar: o minidicionário da língua portuguesa. 4. ed. Rio de Janeiro: Nova Fronteira, 2001. 
FRANCO JÚNIOR, Hilário. A Eva Barbara: ensaios de mitologia. São Paulo: EDUSP, 1996.

GOLDSTEIN, Norma. Versos, sons, ritmos. 13. ed. São Paulo: Editora Filiada, 2004.

LOPES-ROSSI, Maria Aparecida Garcia. Procedimentos para estudo de gêneros discursivos da escrita. Revista Intercâmbio, São Paulo, v. 15, p. 1-10, 2006.

LOPES-ROSSI, Maria Aparecida Garcia. Sequência didática para a leitura de cordel em sala de aula. Revista do GELNE, Natal, v. 14, n. 1-2, p. 145-164, 2012. Disponível em: <http://www.gelne.org.br>. Acesso em: 25 out. 2014.

MARCUSCHI, Luiz Antonio. Produção textual, análise de gêneros e compreensão. São Paulo: Parábola, 2008.

MAZZURANA, Nelso Hahn. +1001 quadrinhas populares da vovó Anita. Porto Alegre: Imprensa Livre, 2008.

MOISÉS, Massaud. A criação literária. 6. ed. São Paulo: Melhoramentos, 1973.

OLIVEIRA, Maria Bernadete F. Contribuições do círculo de Bakhtin ao ensino da língua materna. Revista do GELNE, Natal, v. 4, n. 1, p. 1-5, 2002. Disponível em: <http://www.gelne.org.br>. Acesso em: 25 out. 2014.

SANTOS NETO, Joaquim Antonio; RIBEIRO, Tânia Cristina Costa. Bumba-meuboi: som e movimento. São Paulo: Iphan, 2011.

SCHNEUWLY, Bernard; DOLZ, Joaquim. Gêneros orais e escritos na escola. Tradução de Roxane e Glaís Sales Cordeiro. Campinas: Mercado das Letras, 2004.

SCHOLES, Robert; KELLOGG, Robert. $A$ natureza da narrativa. Tradução de Gert Meyer. São Paulo: Mcgrau-Hill do Brasil, 1977.

SCOTTINI, Alfredo. Dicionário escolar da língua portuguesa. Blumenau: Todolivro, 2009.

SOUZA, Gilda de Melo. O tupi e o alaúde: uma interpretação de Macunaíma. São Paulo: Duas Cidades, 2003.

SPINA, Segismundo. Manual de versificação românica medieval. 2. ed. São Paulo: Ateliê, 2003.

SPINA, Segismundo. Na madrugada das formas poéticas. São Paulo: Ática, 1982. 
STAIGER, Emil. Conceitos fundamentais da poética. Tradução de Celeste Aída Galeão. Rio de Janeiro: Tempo Brasileiro, 1972.

TEIXEIRA, Raquel Dias. Foi São Benedito quem me trouxe aqui: devoção e tradição entre congadas e moçambiques do Vale do Paraíba. Rio de Janeiro: EPHAN, 2012.

WANKE, Eno Teodoro. $A$ trova literária: história da quadra setissilábica autônoma, especialmente na literatura brasileira. Rio de Janeiro: Folha Carioca, 1976.

WANKE, Eno Teodoro. A trova popular. Rio de Janeiro: Pongentti, 1974.

WANKE, Eno Teodoro. A trova: conceituando, origem, história e presença da quadra em redondilha maior. Rio de Janeiro: Editora Pongentti, 1973.

ZUMTHOR, Paul. Introdução à poesia oral. Tradução de Jerusa Pires Ferreira, Maria Lúcia Diniz Pochat e Maria Inês de Almeida. Belo Horizonte: UFMG, 2010. 